\title{
Abnormal expression of b10 cell frequencies: possible relation to pathogenesis and disease severity of aplastic anemia
}

\author{
Lihua Gu' \\ (iD) Bin Fu \\ Diaohui Sui ${ }^{2}$ \\ (iD) Hongzhi Xu'
}

1. Department of Hematology, Shandong Provincial Hospital Affiliated to Shandong University, Jinan, China 2. The Department of Hematology of Heze Municipal Hospital, Heze, China

http://dx.doi.org/10.1590/1806-9282.65.5.637

\section{SUMMARY}

OBJECTIVE: Aplastic anemia (AA) is an immune-mediated disease that destroys hematopoietic cells through activated T lymphocytes. $B$ lymphocyte-mediated humoral immunity also plays an important role in the pathogenesis of AA. Regulatory B cell (Breg) subpopulation, which is defined as "B10", secretes interleukin 10 (IL-10). The objective of our experiment was to investigate whether the scaledown proportion of $B 10$ cells in AA patients may play a key role in the pathogenesis.

METHODS: A total of 38 AA patients (14 SAA patients and 24 NSAA patients) and 20 healthy control subjects were included. All subjects did not suffer from autoimmune diseases or any other diseases affecting the immune system, such as infectious diseases. Bone marrow mononuclear cells (PBMCS) were isolated and analyzed by Flow cytometry (FCM) and Immunofluorescence double-labeling assay. The relationship between the relative proportions of $B 10$ and ProB10 and their associations to $A A$, as well as disease severity, were assessed by common clinical indicators and then examined.

RESULTS: Our analyses revealed AA patients had significantly lower proportions of peripheral B10 and B10pro compared to healthy controls. SAA patients had a substantially lower percentage of B10 cells and B10pro cells compared to NSAA patients. In addition, B10 cells and B10pro cells were negatively correlated with absolute neutrophil counts, hemoglobin levels and platelet, and absolute reticulocyte counts in AA patients.

CONCLUSIONS: The present study attempted to elucidate the potential role of the scale-down proportion of B10 cells in the pathogenesis of $A A$.

KEYWORDS: Anemia, Aplastic. B-Lymphocytes, Regulatory. Interleukin-10.

\section{INTRODUCTION}

Aplastic anemia (AA) is an immune-mediated bone marrow failure disease. The clinical manifestations of AA include pancytopenia and bone marrow pimelosis ${ }^{1}$. The main pathogenesis of AA involves the reduced hematopoietic capacity of the bone mar- row caused by the abnormal activation and proliferation of CD4+ T and CD8+ $\mathrm{T}$ cells and the abnormal secretion of cytokines ${ }^{2,3}$.

B cells not only play a central role in humoral immunity but also regulate the responses of CD4+ T

DATE OF SUBMISSION: 01-Sep-2018

DATE OF ACCEPTANCE: 09-Jan-2019

CORRESPONDING AUTHOR: Hongzhi Xu

Department of Hematology, Shandong Provincial Hospital Affiliated to Shandong University, 324 Jing Wu Road, Jinan, Shandong 250021,

China. - Jinan - 86250001

E-mail: xuhongzhi1965@sina.com 
cells to foreign and autologous antigens. The study conducted by Hansen et al. ${ }^{4}$ demonstrated that the rituximab monoclonal antibody can effectively treat AA once it binds to cluster of differentiation 20 (CD20) on B cells. In the pathogenesis of AA, the effect of abnormal immune function of B cells cannot be ignored ${ }^{5}$. Breg refers to the B cell subpopulation that has negative immunoregulatory effects and secretes negative regulatory factors, such as IL-10, TGF- $\beta$, FoxP3 and IL- $35^{6}$. Among all Bregs, the cells capable of secreting IL-10 are defined as "B10" cells ${ }^{7}$. B10 cells regulate the immune response mainly through secreting the negative regulatory factor IL10. Human and mouse studies have shown that IL10 exhibits a variety of multi-directional activities both in vivo and in vitro ${ }^{6,8-11}$. IL-10 inhibits the proliferation of CD4+ $\mathrm{T}$ cells and the production of the interferon gamma (IFN $\gamma$ ) cytokine by CD4+ T cells. IL-10 also suppresses the differentiation of Thl7h and type $1 \mathrm{~T}$ helper (Th1) cells while inducing the differentiation of naïve T-cells (Th0 cells) toward Th2, thereby affecting the Th1/Th2 balance. Furthermore, IL-10 inhibits the activation of antigen-presenting cells (APCs), macrophages and DCs and suppresses the secretion of proinflammatory cytokines from these cells. In addition, a variety of disease models have demonstrated that IL-10 plays important roles in Treg differentiation and maintenance ${ }^{12}$. The number of Foxp3 + Tregs increases with the amount of B cell-secreted IL-10. In addition to regulating immune responses through the secretion of negative regulatory cytokines, B10 cells act directly on CD4+ T cells via intercellular contacts. For example, B10 cells establish contact with effector T cells through CD40/ CD4OL, resulting in T cell death ${ }^{13-15}$. Many studies have shown that B10 cells deliver negative immunoregulatory effects in systemic lupus erythematosus (SLE), rheumatoid arthritis, psoriasis, multiple sclerosis, and other immune system disorders through IL-10 secretion ${ }^{16-19}$. However, the role of B10 cells in $\mathrm{AA}$, an immune-mediated hematologic disease, remains unclear.

Since the cluster of differentiation 19 (CD19) is expressed throughout all stages of B cell development, CD19+ B cells were used as B cell markers in the present study. Due to the low proportions of B10 cells and progenitor B10 (B10pro) cells in the human body, the function of B10 cells was determined by analyzing IL-10 cytoplasmic expression levels after $5 \mathrm{~h}$ of in vitro cell culture and stimulation, and the activity of B10pro cells was evaluated by analyzing IL-10 cytoplasmic expression levels after $48 \mathrm{~h}$ of in vitro cell culture and stimulation ${ }^{20}$. For the first time, this study compared the percentages of bone marrow-derived B10 cells and B10 + B10pro cells in CD19+ B cells among patients with severe aplastic anemia (SAA), patients with non-severe aplastic anemia (NSAA) and healthy controls. Also, the present study analyzed the correlations between the proportions of the above cells in the bone marrows of SAA and NSAA patients and the indices reflecting the severity of bone marrow hyperplasia. The purpose of the present study was to explore the potential role and significance of B10 cells in the pathogenesis of $\mathrm{AA}$ and provide new clues for the future development of immunotherapy for AA.

\section{METHODS}

\section{Research objects}

A total of 38 AA patients who had been outpatients or inpatients in the Shandong Provincial Hospital Affiliated with Shandong University between February 2017 and July 2017 were included in the present study. Diagnoses were in accordance with the "Diagnostic criteria and therapeutic principles of hematologic diseases". Among the 38 AA patients, 14 patients suffered from SAA. The 14 patients included 7 males and 7 females, and the median age was 36 (14-65) years. The remaining 24 patients had NSAA; 14 of them were males and 10 were females. The median age of the NSAA patients was 36 (14-65) years. None of the 38 patients had a prior history of blood diseases. The patients did not suffer from autoimmune diseases or any other diseases affecting the immune system, such as infectious diseases. In addition, 20 healthy volunteers whose age and sex compositions were well matched with the above patients were selected as normal controls. All subjects and their family members signed informed consent documents. The study was approved by the Academic Ethics Committee of the hospital.

\section{Bone marrow collection and in vitro cell culture}

After $5 \mathrm{~h}$ of in vitro culture and stimulation, the IL-10 content in CD19+ cells reflected the changes in the levels of bone marrow-derived B10 cells. In the present study, bone marrow mononuclear cells (BMMNCs) were stimulated for $5 \mathrm{~h}$ with a combination of phorbol ester, ionomycin, PIB, CpG and CD4OL. Af- 
ter $48 \mathrm{~h}$ of in vitro culture and stimulation, the IL-10 content in CD19+ cells reflected the changes in the levels of bone marrow-derived B10 + B10pro cells. In the present study, BM-MNCs were stimulated with $\mathrm{CpG}$ and CD4OL for $48 \mathrm{~h}$. In addition, PIB stimulation was applied during the last $5 \mathrm{~h}$.

Bone marrow samples $(20 \mathrm{~mL})$ were harvested from the AA patients and the age- and sex-matched healthy controls and were placed in collection tubes with heparin anticoagulant (BD Biosciences). After the addition of an equal volume of lymphocyte separation medium (Tianjin HaoYang Biological Manufacture Co., Ltd.) to the tubes, Ficoll density gradient centrifugation was performed at room temperature to isolate the mononuclear cells. Subsequently, cell viability was examined using Trypan blue (Beijing Solarbio Science \& Technology Co., Ltd.). The percentage of viable cells exceeded $96 \%$, indicating that the cell preparation could be used in the subsequent experiments. The isolated mononuclear cells were resuspended in the Roswell Park Memorial Institute (RPMI) 1640 medium (Biological Industries) containing $10 \%$ calf serum (Biological Industries) at a concentration of $2 \times 10^{6}$ cells $/ \mathrm{L}$ and were then seeded into 24-well tissue culture plates. The cells were divided into a 5-h culture group and a 48 -h culture group. The controls were divided in the same manner. The 5-h culture group was treated as follows: First, phorbol ester (25 ng/mL, MultiSciences (Lianke) Biotech Co., Ltd.), ionomycin (0.5 $\mu \mathrm{g} / \mathrm{mL}$, MultiSciences (Lianke) Biotech Co., Ltd.) and Brefeldin A (PIB, $0.5 \mu \mathrm{L} / \mathrm{mL}$, MultiSciences (Lianke) Biotech Co., Ltd.) were added to each well of the cells. Subsequently, the cells were stimulated with $5-\mu \mathrm{g} / \mathrm{mL}$ CpG (ODN 7909, InvivoGen) and $0.5-\mu \mathrm{g} / \mathrm{mL}$ CD40 ligand (CD4OL, R\&D Systems) for $5 \mathrm{~h}$. The 48 -h culture group was stimulated with $5 \mu \mathrm{g} / \mathrm{mL}$ CpG and $0.5 \mu \mathrm{g} / \mathrm{mL}$ CD4OL for $48 \mathrm{~h}$. PIB stimulation was applied during the last $5 \mathrm{~h}$. All cells were cultured in an incubator at $37^{\circ} \mathrm{C}$ and in an atmosphere of $5 \% \mathrm{CO} 2$.

\section{Flow cytometric (FCM) analysis}

The stimulated cells were collected in fluorescence-activated cell sorter (FACS) tubes, washed once with $3 \mathrm{~mL}$ of phosphate-buffered saline (PBS) and centrifuged at 1,000 r/min for $5 \mathrm{~min}$. The supernatants were discarded. Subsequently, $20 \mu \mathrm{L}$ of the anti-human cluster of differentiation 19 (CD19) antibody (BD Biosciences) was added to each tube of cells. After incubation for $20 \mathrm{~min}$ at room tempera- ture in the dark, the cells were washed once with 2 $\mathrm{mL}$ of PBS (centrifugation at 1,000 r/min for $5 \mathrm{~min}$ ), and the supernatants were again discarded. The cells were then incubated with $500 \mu \mathrm{L}$ of Fixation/Permeabilization Solution (BD Biosciences) for $20 \mathrm{~min}$ at room temperature in the dark. After centrifugation at $500 \mathrm{xg}$ for $5 \mathrm{~min}$, the supernatants were discarded. The cells were fixed in $2 \mathrm{~mL}$ of $1 \mathrm{xWash}$ Buffer for $10 \mathrm{~min}$ at room temperature in the dark and then centrifuged at 500xg for $5 \mathrm{~min}$. After removal of the supernatants, the cells were incubated with $5 \mu \mathrm{L}$ of allophycocyanin-labeled anti-human IL-10 antibody (BD Biosciences) for $30 \mathrm{~min}$ at room temperature in the dark. The cells were then washed twice with 2 $\mathrm{mL}$ of PBS (centrifugation at 1,000 r/min for $5 \mathrm{~min}$ ). The resulting supernatants were discarded, and the cells were resuspended in $400 \mu \mathrm{L}$ of PBS. The experimental results were analyzed by flow cytometry (BD Biosciences, CellQuest software).

\section{Immunofluorescence double-labeling assay}

Bone marrow-derived mononuclear cells growing on glass coverslips were stimulated in vitro for $5 \mathrm{~h}$ and $48 \mathrm{~h}$. Once the cells were dried slightly, they were incubated with 50-100 $\mu \mathrm{L}$ of fixation/permeabilization solution at room temperature for $20 \mathrm{~min}$ and then washed 3 times with PBS, each wash for 5 min. To block the non-specific binding of the antibody, the cells were evenly covered with $3 \%$ bovine serum albumin (BSA) solution and blocked at room temperature for $30 \mathrm{~min}$. (When the primary antibody was derived from goat, $10 \%$ normal rabbit serum was used as the blocking reagent. When the primary antibody was raised in a species other than goats, 3\% BSA was used as the blocking reagent.) After incubation, the blocking solution was gently shaken off. Rabbit anti-CD19 monoclonal antibody (purchased from Abcam, UK; diluted 1:100 in PBS) and mouse anti-IL-10 monoclonal antibody (purchased from Biolegend Company, USA; diluted 1:100 in PBS) were added dropwise to the cell culture plates. The plates were placed in a humidified container and incubated at $4^{\circ} \mathrm{C}$ overnight. Following incubation with the primary antibodies, the plates were washed 3 times (5 minutes each) on a shaker and dried slightly by shaking off the wash buffer. Subsequently, the cells were covered with the solution containing the corresponding secondary antibody (1:400 dilution, purchased from Servicebio, China) and incubated at room temperature for 50 min (the anti-CD19 antibody was directly conjugated 
Figure 1

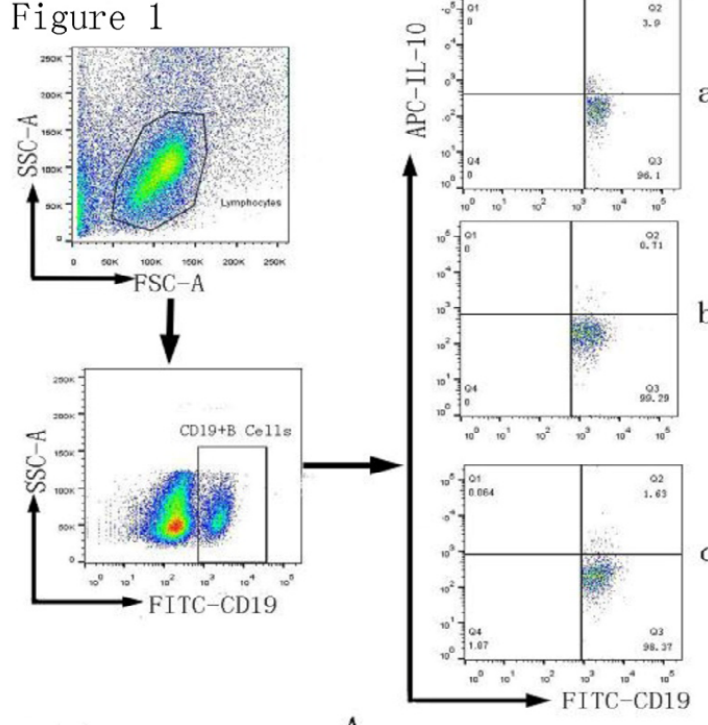

A

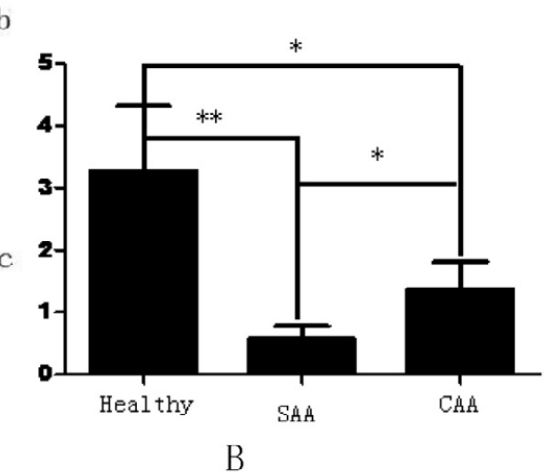

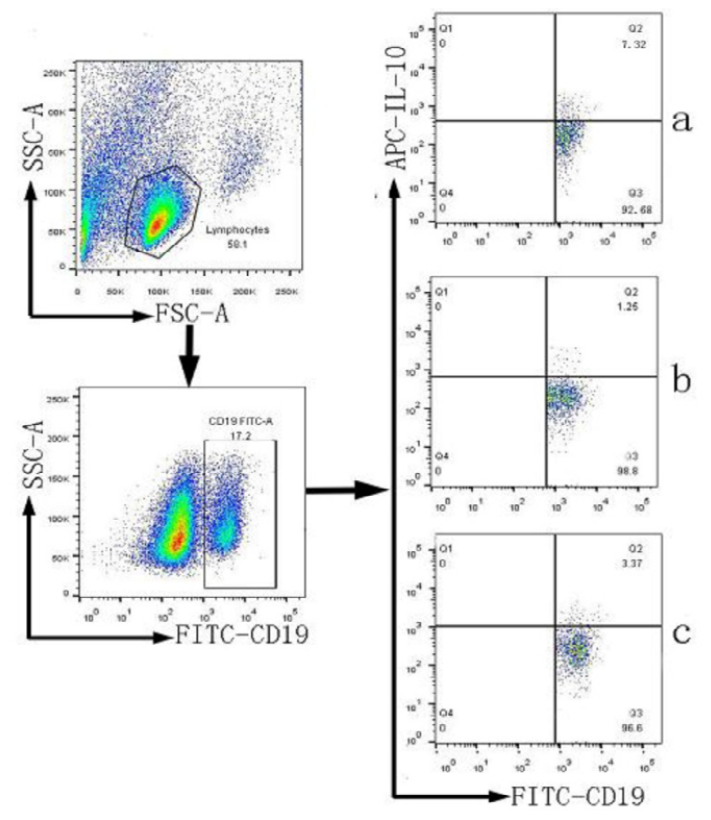

C

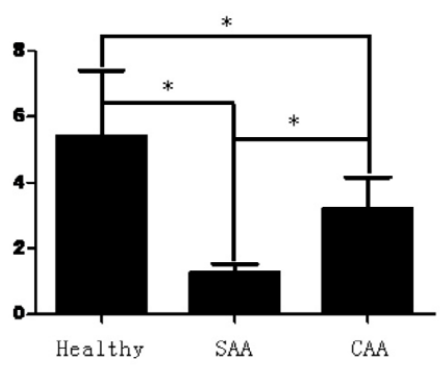

D

FIGURE 1 (A-B): Presence of B10 cells in the SAA, NSAA, and healthy control groups: Side scatter (SSC-A) measures intracytoplasmic granules, while forward scatter (FSC-A) measures cell size. To reflect the changes in the percentages of B10 cells, BMMNCs were stimulated in vitro with a combination of phorbol ester, ionomycin, PIB, CpG and CD4OL for $5 \mathrm{~h}$. A (a). The ratio of B10 cells to CD19+ B cells in the healthy control group. A (b). The ratio of B10 cells to CD19+ B cells in the SAA group. A (c). The ratio of B10 cells to CD19+ B cells in the NSAA group. $B$. The ratio of B10 cells to CD19+ B cells in SAA patients $(0.57 \pm 0.21 \%)$ vs. the healthy control group (3.28 $\pm 1.04 \%)$; the ratio of $B 10$ cells to CD19+ B cells in NSAA patients $(1.38 \pm 0.43 \%)$ vs. the healthy control group ( $3.28 \pm 1.04 \%)$; the ratio of B10 cells to CD19+ B cells in SAA patients $(0.57 \pm 0.21 \%)$ vs. NSAA patients $(1.38 \pm 0.43 \%)$. The results of statistical significance testing were as follows: ${ }^{*}$ represents $P<0.05 ;{ }^{* *}$ represents $P<0.01$.

FIGURE 1 (C-D): Percentages of B10 + B10pro cells in AA patients and the healthy control group: Side scatter (SSC-A) measures intracytoplasmic granules, while forward scatter (FSC-A) measures cell size. In the present study, BM-MNCs were stimulated with CpG and CD4OL for 48h. In addition, PIB stimulation was applied during the last 5h. The percentages of B10 + B10pro cells in CD19+ B cells were determined in AA patients and the healthy control group. A (a). The ratio of B10 + B10pro cells to CD19+ B cells in the healthy control group. $A(b)$. The ratio of B10 + B10pro cells to CD19+ B cells in the SAA group. $A$ (c). The ratio of B10 + B10pro cells to CD19+ B cells in the NSAA group. (B). The ratio of B10 + B10pro cells to CD19+ B cells in SAA patients (1.28 $\pm 0.25 \%)$ vs. the healthy control group (5.42 $\pm 1.99 \%)$; the ratio of B10 + B10pro cells to CD19+ B cells in NSAA patients $(3.2 \pm 0.96 \%)$ vs. the healthy control group $(5.42 \pm 1.99 \%)$; the ratio of B10 + B10pro cells to CD19+ B cells in SAA patients $(1.28 \pm 0.25 \%)$ vs. NSAA patients $(3.2 \pm 0.96 \%)$. The results of statistical significance testing were as follows: ${ }^{*}$ represents $P<0.05$;

${ }^{* *}$ represents $\mathrm{P}<0.01$. 
to a label, and no secondary antibody was needed). The coverslips were placed on a shaker and washed 3 times in PBS (pH 7.4) for 5 min each with shaking. The coverslips were dried slightly by shaking off the wash buffer. To counterstain the nuclei, 4',6-diamidino-2-phenylindole (DAPI) was added dropwise to the coverslips and incubated for $10 \mathrm{~min}$ at room temperature in the dark. The coverslips were again placed on a shaker and washed 3 times in PBS (pH 7.4) for 5 min each with shaking. The coverslips were dried slightly by shaking off the wash buffer and mounted using an anti-quenching mounting medium. The slides were observed under a fluorescence microscope, and images were collected. Semi-quantitative analysis was performed using TissueQuest 4.0.1.0140 software. The relative counts of the $\mathrm{CD} 19^{+} \mathrm{IL}-1 \mathrm{O}^{+} \mathrm{B}$ cells in the bone marrow-derived mononuclear cells after 5 and $48 \mathrm{~h}$ of in vitro stimulation were determined by calculating the ratios of the numbers of CD19 and IL-10 dots to the number of DAPI dots.

\section{Clinical evaluation}

Complete medical histories were obtained from all patients, and physical examinations were performed. In addition, fasting peripheral blood was collected from the two groups of patients in the early morning shortly after the patients awoke. The absolute neutrophil counts, hemoglobin levels and platelet and absolute reticulocyte counts were determined by routine blood testing.

\section{Statistical analysis}

Statistical analysis was conducted using SPSS19.0 software. The measurement data are expressed as $\mathrm{x} \pm \mathrm{s}$. The $\mathrm{t}$-test was employed to determine whether statistically significant differences existed between the means of two groups. Correlation analysis was performed using Linear correlation. A p-value lower than 0.05 indicated that the difference was statistically significant.

\section{RESULTS}

Regarding the percentage of B10 cells and B10+B10pro cells in AA patients versus healthy controls.

\section{Flow cytometric analysis:}

1) In bone marrow derived from SAA patients, B10 cells accounted for $0.57 \pm 0.21 \%$ of the CD19+ B cells, while in the normal control group, B10 cells ac- counted for $3.28 \pm 1.04 \%$ of the CD19+ B cells; the difference was statistically significant $(\mathrm{t}=6.26, \mathrm{P}<0.01)$. Similarly, the percentage of B10 cells in the CD19+ B cells was statistically significantly lower in the bone marrow derived from NSAA patients $(1.38 \pm 0.43 \%)$ in comparison to the normal control group (3.28 $\pm 1.04 \%)$ $(\mathrm{t}=4.14, \mathrm{P}<0.05)$. Moreover, the percentage of $\mathrm{B} 10$ cells in the CD19+ B cells was statistically significantly lower in the bone marrow derived from SAA patients $(0.57 \pm 0.21 \%)$ in comparison to the bone marrow derived from NSAA patients $(1.38 \pm 0.43 \%)(\mathrm{t}=4.12$, $\mathrm{P}<0.05)$. The results are shown in Figure $1(\mathrm{~A}-\mathrm{B})$.

2)The percentage of $\mathrm{B} 10+$ B10pro cells in the CD19+ B cells was lower in the bone marrow derived from SAA patients $(1.28 \pm 0.25 \%)$ in comparison to the normal control group $(5.42 \pm 1.99 \%)$, and the difference was statistically significant $(\mathrm{t}=5.07, \mathrm{P}<0.05)$. Similarly, the percentage of B10 + B10pro cells in CD19+ B cells was statistically significantly lower in the bone marrow derived from NSAA patients $(3.2 \pm 0.96 \%)$ in comparison to the normal control group $(5.42 \pm 1.99 \%)$ $(\mathrm{t}=2.47, \mathrm{P}<0.05)$. Moreover, the percentage of $\mathrm{B} 10+$ B10pro cells in CD19+ B cells was statistically significantly lower in the bone marrow derived from SAA patients $(1.28 \pm 0.25 \%)$ in comparison to the bone marrow derived from NSAA patients $(3.2 \pm 0.96 \%)(\mathrm{t}=4.76$, $\mathrm{P}<0.05)$. The results are shown in Figure $1(\mathrm{C}-\mathrm{D})$.

\section{Immunofluorescence assay}

1) The results of the semi-quantitative immunofluorescence assay were as follows. Compared with the healthy controls(A), the percentages of CD19 + IL-10 + B10 cells in CD19+ B cells were decreased in SAA(C) and NSAA(B) patients after stimulating the BM-MNCs in vitro for 5h. Moreover, the percentage of CD19 + IL-10 + B10 cells was lower in SAA patients in comparison to NSAA patients. The results are shown in Figure 2 (a).

2). The results of the semi-quantitative immunofluorescence assay were as follows: after stimulating the BM-MNCs in vitro for $48 \mathrm{~h}$, the percentages of B10 + B10pro cells in CD19+ B cells were lower in SAA(B) and NSAA(C) patients compared with the healthy controls(A). Moreover, the percentage of B10 + B10pro cells was lower in SAA patients in comparison to NSAA patients. The results are shown in Figure 2 (b).

The percentages of $\mathrm{B} 10$ cells and $\mathrm{B} 10+\mathrm{B} 10$ pro cells in the bone marrows of AA patients were negative with the neutrophil, reticulocyte and platelet counts. 


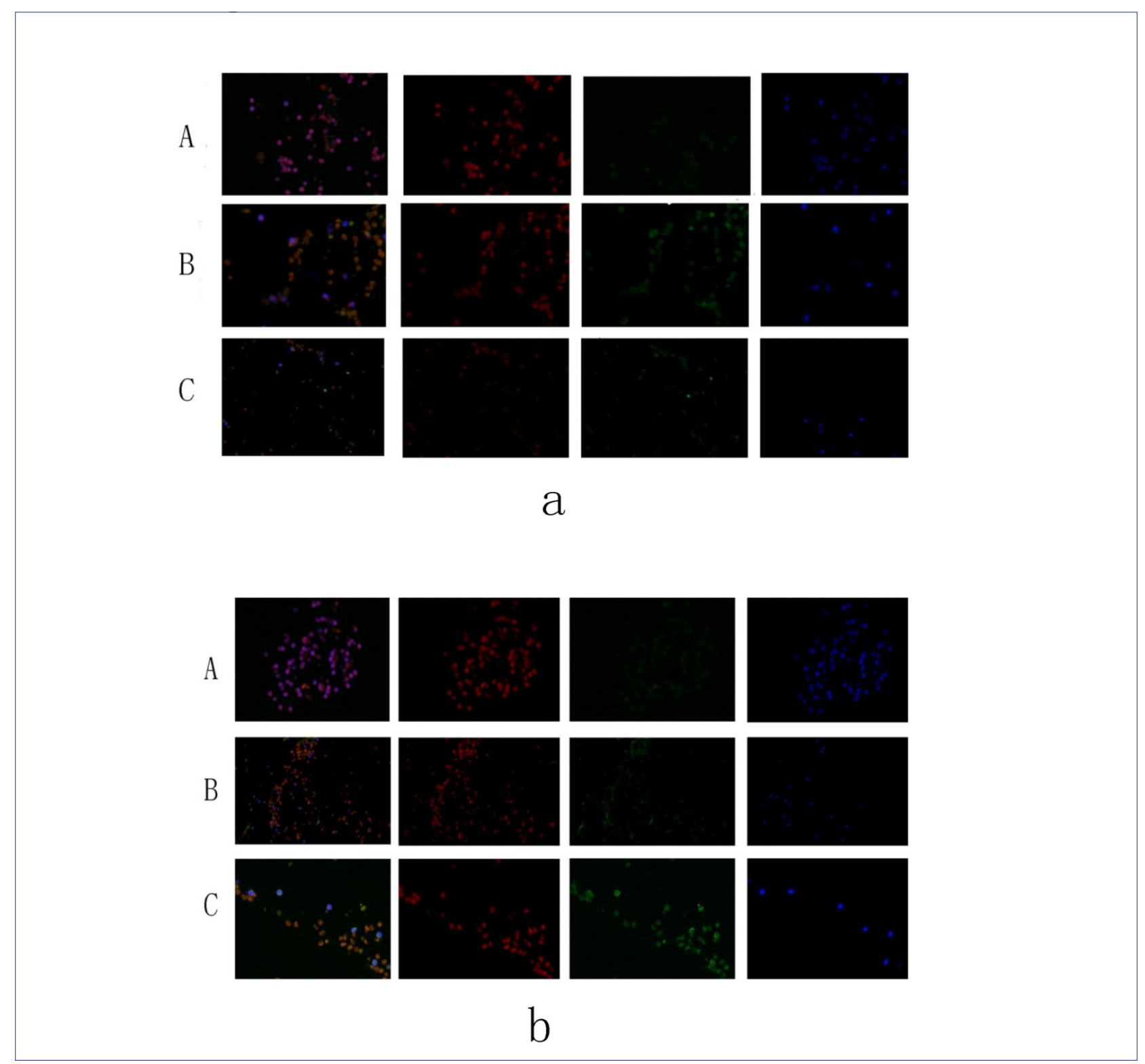

\section{FIGURE 2(A-B)}

Blue - nucleus; Green - CD19 (located in cell membranes); Red - IL-10 (located in the nucleus or the cytoplasm). B10pro cells in the bone marrows of AA patients and the neutrophil, reticulocyte, and platelet counts

1) In patients with SAA, the ratio of B10 cells to CD19+ B cells was positively correlated with peripheral blood neutrophil, reticulocyte and platelet counts. In patients with NSAA, the percentage of B10 cells was positively correlated with peripheral blood neutrophil, reticulocyte and platelet counts. The results are shown in FIGURE $\mathbf{3 ( A )}$.

2) In patients with SAA, the ratio of B10 + B10pro cells to CD19+ B cells was positively correlated with peripheral blood neutrophil, reticulocyte and platelet counts. In patients with NSAA, the ratio of B10 + B10pro cells to CD19+ B cells was also positively correlated with peripheral blood neutrophil, reticulocyte and platelet counts. The results are shown in FIGURE 3(B).

The peripheral blood neutrophil, reticulocyte and platelet counts were decreased in SAA patients compared with the healthy control group. Similarly, the peripheral blood neutrophil, reticulocyte and platelet counts were decreased in NSAA patients compared with the healthy control group. Moreover, the peripheral blood neutrophil, reticulocyte and platelet counts were reduced in SAA patients in comparison to NSAA patients. The results are summarized in FIGURE 3(C).

1) In patients with $S A A$, the ratio of B10 cells to CD19+ B cells was positively correlated with peripheral blood neutrophil, reticulocyte and platelet counts. In patients with NSAA, the percentage of B10 cells was positively correlated with peripheral blood neutrophil, reticulocyte and platelet counts. The results are shown in Figure 3 (a).

2) In patients with SAA, the ratio of B10 + B10pro cells to CD19+ B cells was positively correlated with peripheral blood neutrophil, reticulocyte and plate- 


\section{Figure 3}
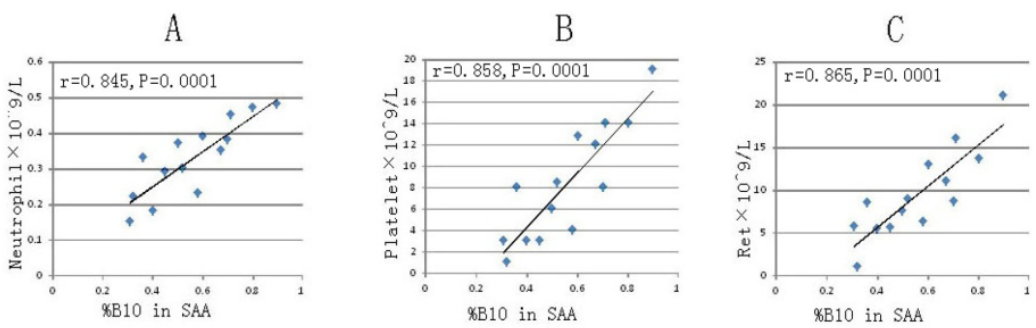

D

$$
\text { F }
$$

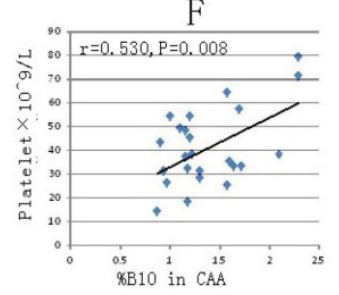

E

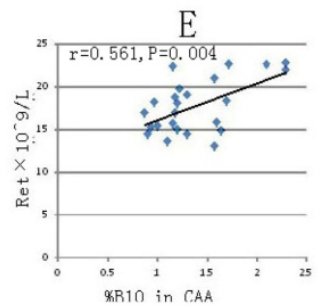

a

A

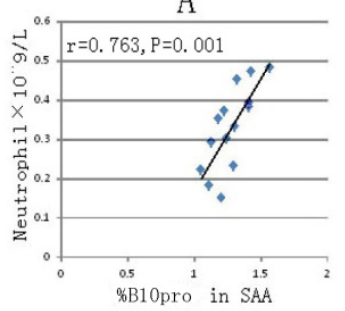

D

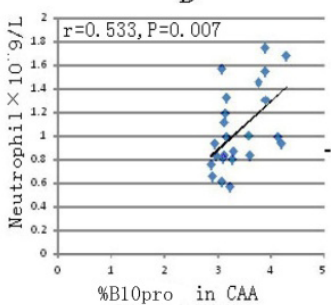

B

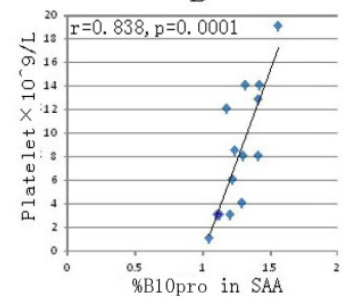

E

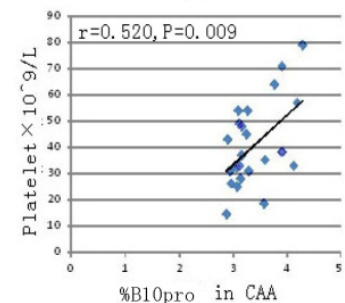

b

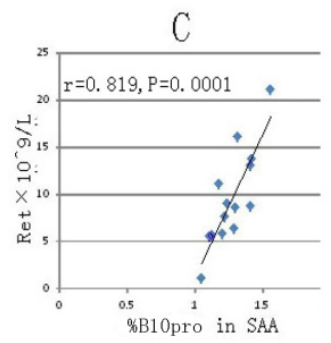

F

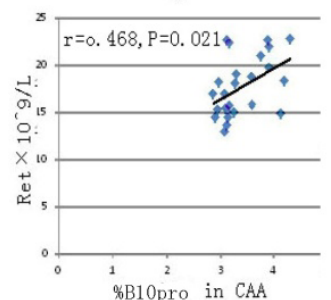

\begin{tabular}{cccc}
\hline Group & Neut $\times 10^{\wedge} 9 / \mathrm{L}$ & Ret $\times 10^{\wedge} 9 / \mathrm{L}$ & $\mathrm{PLT} \times 10^{\wedge} 9 / \mathrm{L}$ \\
\hline SAA & $0.33 \pm 0.11 * *$ & $8.31 \pm 5.37 * * \boldsymbol{\Delta}$ & $\begin{array}{c}8.57 \pm 4.04 * * \\
\text { NSAA }\end{array}$ \\
Healthy & $4.05 \pm 0.34 * *$ & $17.71 \pm 3.16 * *$ & $40.96 \pm 16.13 * *$ \\
& $4.7 \pm 1.0$ & $65.0 \pm 6.1$ & $229.5 \pm 41.8$
\end{tabular}

$* \mathrm{P}<0.05, \quad * * \mathrm{P}<0.01, \quad$ compared with Healthy group; $\mathbf{\Delta} \mathrm{P}<0.05, \quad \mathbf{\Delta} \Delta \mathrm{P}<$

0. 01, compared with NSAA group. . Neut: neutrophil ; Ret:ret; PLT: palette.

C 
let counts. In patients with NSAA, the ratio of B10 + B10pro cells to CD19+ B cells was also positively correlated with peripheral blood neutrophil, reticulocyte and platelet counts. The results are shown in Figure $3(b)$.

3) The peripheral blood neutrophil, reticulocyte and platelet counts were decreased in SAA patients compared with the healthy control group. Similarly, the peripheral blood neutrophil, reticulocyte and platelet counts were decreased in NSAA patients compared with the healthy control group. Moreover, the peripheral blood neutrophil, reticulocyte and platelet counts were reduced in SAA patients in comparison to NSAA patients. The results are summarized in Figure 3 (c).

\section{DISCUSSION}

For the first time, our present study showed that the percentages of bone-marrow-derived B10 cells in CD19+ B cells were lower in AA groups compared with the healthy control group using flow cytometric analysis and immunofluorescence assays. Moreover, the percentage of B10 cells was lower in the SAA group in comparison to the NSAA group. Also, the correlations between the percentages of B10 cells and the clinical parameters that reflected the severity of bone marrow hyperplasia were positive. Therefore, B10 cells are likely to play a pivotal role in the pathogenesis of AA.

$\mathrm{AA}$ is an autoimmune disease characterized by $\mathrm{T}$ cell hyperfunction-induced bone marrow hematopoietic tissue damage. The specific pathogenesis of AA is still not clear. Tregs maintain homeostasis, induce immune tolerance and prevent the occurrence of autoimmune diseases. However, the numbers of Tregs are decreased in the peripheral blood and bone marrows of AA patients, resulting in an inability to inhibit effector T cells normally ${ }^{21}$. However, the role of B10 cells in AA, an immune-mediated hematologic disease, remains unclear.

In the human body, $\mathrm{T}$ lymphocyte-mediated cellular immunity and B lymphocyte-mediated humoral immunity mutually influence and complement each other. Some scholars believe that the immune disorder in AA is also correlated with B cell-mediated humoral immunity ${ }^{5}$ since kinectin, moesin and DRS-1 antibodies have been detected in the sera of AA patients ${ }^{22-24}$. B10 cells are a particular subpopulation of $\mathrm{B}$ cells with negative immunoregulatory capability. The immunoregulatory activity of B10 cells in immune responses has attracted special attention. Studies show that IL-10 regulates the Th1/ Th2 balance, induces the apoptosis of effector $\mathrm{T}$ cells, reduces the production of tumor necrosis factor alpha (TNF $\alpha$ ), IFN $\gamma$ and other inflammatory factors and downregulates autoimmune and excessive immune responses ${ }^{20,25}$. In our study, B10 cells and B10 + B10pro cells levels were lower in AA patients than in healthy individuals; and we also found a correlation with severity. B10 cells promote Treg cell differentiation and simultaneously inhibit inflammatory cytokine production by $\mathrm{T}$ effector cells. Kessel et al. ${ }^{26}$ found that B10 enhances the expression levels of Foxp3 and cytotoxic T lymphocyte-associated antigen 4 (CTLA-4) in Tregs through direct cell-cell contact. The decrease in the percentage of B10 cells limited the secretion of the negative regulatory factor IL-10. As the amount of B10 cell-secreted IL-10 decreases, the above immunosuppressive effects decline accordingly in AA patients. In summary, B1O cells may act on $\mathrm{T}$ cells and other related immune cells through IL-10 secretion and intercellular contact, thereby exerting a negative immunoregulatory effect.

The progenitor B (pro-B) cell stage is critical in B cell development and maturation. Pro-B cells have the potential to develop into mature B cells. Many studies have shown that the percentage of B10 + B10pro cells is increased in the peripheral blood of patients with various immune system disorders in comparison to the healthy control group ${ }^{20}$. The present study found that the percentages of B10 + B10pro cells in CD19+ $\mathrm{B}$ cells were decreased in the bone marrows of AA patients compared with the healthy control group, and correlation with severity. The above data suggest that B10pro cells may be damaged or experience differentiation disorder or obstacles exist in the process of B10pro cell development toward mature B10 cells in AA patients. While the specific factors that cause the injury and differentiation disorder have yet to be identified.

A previous study showed that in patients with AA, IL-10 promotes the growth of hematopoietic progenitor cells and enhances erythrocyte colony formation ${ }^{22}$. The decrease in absolute neutrophil, platelet and reticulocyte counts indicated the severity of AA. The statistical results of the present study showed that the absolute neutrophil, platelet, and reticulocyte counts in the peripheral blood of pa- 
tients with SAA and NSAA were positively correlated with the ratio of B10 cells to CD19+ B cells in the bone marrow. The above results indicate that the decrease in the percentage of B10 cells contributes to the pathogenesis of $\mathrm{AA}$ and is related to the severity of $\mathrm{AA}$. The lower the B10 cell level, the more severe the disease is.

The present study found that the percentages of B10 cells and B10 + B10pro cells in CD19+ B cells were decreased in the bone marrows of AA patients in comparison to the healthy control group. Such a finding suggests that B10 cells inhibit DCs, APCs, and macrophages and attenuate the activity of effector $\mathrm{T}$ cells, thereby affecting $\mathrm{T}$ cell-mediated immunity. This finding is conducive to the understanding of the potential role of $\mathrm{B} 10$ cell ratio changes in the pathogenesis of AA. It is not clear whether the function of B10 cells is normal in the bone mar- row of AA patients and whether there are defects in B10 cell-activating signals in the bone marrow. The inhibition of B10 cells in abnormal T cell-mediated immunity and the targets of B10 cells in AA are also unclear. The potential immune functions of B10 cells in the pathogenesis of AA need to be further explored.

\section{Conflict of interests}

The authors declare no conflicts of interests.

\section{Acknowledgments}

This work was supported by grants from the National Science Foundation of Shandong (No.2016GSF201049), the key research and development project of Province (No. 2015GSF118058) and the Key Research and Development Project of Shandong Province (No. 2015GSF118025)

\section{RESUMO}

OBJETIVO: A anemia aplástica (AA) é uma doença imunomediada que destrói células hematopoiéticas por meio dos linfócitos T ativados. A imunidade humoral mediada por linfócitos $B$ também desempenha um papel importante na patogênese da $A A$. A subpopulação de células B reguladoras (Breg), que é definida como "B10", secreta interleucina 10 (IL-10). No experimento, investigou-se se a proporção reduzida de células $B 10$ nos pacientes de $A A$ pode desempenhar um papel-chave na patogênese.

MÉTODOS: Um total de 38 pacientes de AA (14 pacientes de anemia aplástica grave e 24 pacientes de anemia aplástica não grave) e 20 indivíduos de controle saudáveis foram incluídos. Todos os indivíduos não sofriam de doenças autoimunes ou de quaisquer outras doenças que afetam o sistema imunológico, tais como doenças contagiosas. As células mononucleares da medula óssea (PBMCs) eram isoladas e analisadas por citometria de fluxo (FCM) e ensaio de dupla marcação por imunofluorescência. A relação entre as proporções relativas de células B10 e as células ProB10 e as suas associações à AA, assim como a gravidade da doença avaliada por indicadores clínicos comuns, foram examinadas.

RESULTADOS: Nossas análises revelaram que os pacientes de AA têm proporções significativamente menores de células B10 e células ProB10 periféricas em comparação com indivíduos de controle saudáveis. Os pacientes de anemia aplástica grave tiveram uma percentagem substancialmente menor de células B10 e células B10pro em comparação com pacientes de anemia aplástica não grave. Além disso, as células B10 e B10pro foram negativamente correlacionadas com contagens absolutas de neutróflos, níveis de hemoglobina e plaquetas e contagem de reticulócitos absolutos nos pacientes de AA.

CONCLUSÕES: Além disso, o estudo presente tentou elucidar o papel imunorregulatório potencial das células B10 na patogênese da AA e fornecer uma nova estratégia para a aplicação de imunoterapia baseada na célula B para tratar a AA no futuro.

PALAVRAS-CHAVE: Anemia aplástica. Linfócitos B reguladores. Interleucina-10.

\section{REFERENCES}

1. Young NS, Bacigalupo A, Marsh JC. Aplastic anemia: pathophysiology and treatment. Biol Blood Marrow Transplant. 2010;16(1 Suppl):S119-25.

2. Young NS, Calado RT, Scheinberg P. Current concepts in the pathophysiology and treatment of aplastic anemia. Blood. 2006;108(8):2509-19.

3. Hu X, Gu Y, Wang Y, Cong Y, Qu X, Xu C. Increased CD4+ and CD8+ effector memory $T$ cells in patients with aplastic anemia. Haematologica. 2009;94(3):428-9

4. Hansen PB, Lauritzen AM. Aplastic anemia successfully treated with rituximab. Am J Hematol. 2005;80(4):292-4.

5. Teramura M, Kobayashi S, Iwabe K, Yoshinaga K, Mizoguchi H. Mechanism of action of antithymocyte globulin in the treatment of aplastic anaemia: in vitro evidence for the presence of immunosuppressive mechanism. Br J Haematol. 1997;96(1):80-4.

6. Mauri C, Bosma A. Immune regulatory function of B cells. Annu Rev Immunol. 2012;30:221-41.

7. Yanaba K, Bouaziz JD, Haas KM, Poe JC, Fujimoto M, Tedder TF. A regulatory $B$ cell subset with a unique CD1dhiCD5+ phenotype controls T cell-dependent inflammatory responses. Immunity. 2008;28(5):639-50.

8. Amu S, Saunders SP, Kronenberg M, Mangan NE, Atzberger A, Fallon PG. Regulatory $B$ cells prevent and reverse allergic airway inflammation via FoxP3-positive T regulatory cells in a murine model. J Allergy Clin Immunol. 2010;125(5):1114-24. 
9. Rieger A, Bar-Or A. B-cell-derived interleukin-10 in autoimmune disease: regulating the regulators. Nat Rev Immunol. 2008;8(6):486-7.

10. Fillatreau S, Gray D, Anderton SM. Not always the bad guys: B cells as regulators of autoimmune pathology. Nat Rev Immunol. 2008;8(5):391-7.

11. Moulin V, Andris F, Thielemans K, Maliszewski C, Urbain J, Moser M. B lymphocytes regulate dendritic cell (DC) function in vivo: increased interleukin 12 production by DCs from B cell-deficient mice results in T helper cell type 1 deviation. J Exp Med. 2000;192(4):475-82.

12. Khare $P$, Bose A, Singh P, Singh S, Javed S, Jain SK, et al. Gonadotropin and tumorigenesis: direct and indirect effects on inflammatory and immunosuppressive mediators and invasion. Mol Carcinog. 2017;56(2):359-70.

13. Gao N, Dresel I, Eckstein V, Gellert R, Störch H, Venigalla RK, et al. Impaired suppressive capacity of activation-induced regulatory $B$ cells in systemic lupus erythematosus. Arthritis Rheumatol. 2014;66(10):284961.

14. Mizoguchi A, Bhan AK. A case for regulatory B cells. I Immunol. 2006;176(2):705-10.

15. Mizoguchi A, Mizoguchi E, Takedatsu H, Blumberg RS, Bhan AK. Chronic intestinal inflammatory condition generates $\mathrm{IL}-10$-producing regulatory $\mathrm{B}$ cell subset characterized by CD1d upregulation. Immunity. 2002;16(2):21930 .

16. Anolik |H, Barnard I, Owen $T$, Zheng B, Kemshetti S, Looney RJ, et al. Delayed memory $B$ cell recovery in peripheral blood and lymphoid tissue in systemic lupus erythematosus after B cell depletion therapy. Arthritis Rheum. 2007:56(9):3044-56.

17. Mauri C, Gray D, Mushtaq N, Londei M. Prevention of arthritis by interleukin 10-producing B cells. J Exp Med. 2003;197(4):489-501.
18. Correale J, Farez M, Razzitte G. Helminth infections associated with multiple sclerosis induce regulatory B cells. Ann Neurol. 2008;64(2):187-99.

19. Onishi Y, Fehervari Z, Yamaguchi T, Sakaguchi S. Foxp3+ natural regulatory $T$ cells preferentially form aggregates on dendritic cells in vitro and actively inhibit their maturation. Proc Natl Acad Sci U S A. 2008;105(29):10113-8.

20. Iwata Y, Matsushita T, Horikawa M, Dilillo D|, Yanaba K, Venturi GM, et al. Characterization of a rare $\mathrm{IL}-10$-competent B-cell subset in humans that parallels mouse regulatory B10 cells. Blood. 2011;117(2):530-41.

21. Shi J, Ge M, Lu S, Li X, Shao $Y$, Huang J, et al. Intrinsic impairment of CD4(+)CD25(+) regulatory $T$ cells in acquired aplastic anemia. Blood. 2012;120(8):1624-32.

22. Hirano N, Butler MO, Von Bergwelt-Baildon MS, Maecker B, Schultze IL, $\mathrm{O}^{\prime}$ Connor KC, et al. Autoantibodies frequently detected in patients with aplastic anemia. Blood. 2003;102(13):4567-75.

23. Takamatsu H, Feng $X$, Chuhjo T, Lu X, Sugimori C, Okawa K, et al. Specific antibodies to moesin, a membrane-cytoskeleton linker protein, are frequently detected in patients with acquired aplastic anemia. Blood. 2007;109(6):2514-20.

24. Qi Z, Takamatsu H, Espinoza JL, Lu X, Sugimori N, Yamazaki H, et al. Autoantibodies specific to hnRNP K: a new diagnostic marker for immune pathophysiology in aplastic anemia. Ann Hematol. 2010;89(12):1255-63.

25. Tedder TF. B10 cells: a functionally defined regulatory B cell subset. I Immunol. 2015;194(4):1395-401.

26. Kessel A, Haj T, Peri R, Snir A, Melamed D, Sabo E, et al. Human CD19(+) CD25(high) $B$ regulatory cells suppress proliferation of CD4(+) T cells and enhance Foxp3 and CTLA-4 expression in T-regulatory cells. Autoimmun Rev. 2012;11(9):670-7. 